\title{
In condoms we trust: to each, one's own
}

\author{
Lindsay Edouard
}

\section{Summary}

Long neglected in the provision of sexual health services, condoms swiftly gained prominence when the sexual transmission of the human immunodeficiency virus (HIV) was recognised. There is excellent evidence for the role of condoms as a barrier for both contraception and the control of sexually transmitted infections (STIs). Now available in various forms, condoms should be promoted widely and efforts made to dispel myths.

\section{Importance of infections}

With increasing rates of pregnancy, gonorrhoea and syphilis among teenagers in England and Wales during the 1970s, Sir George Young, the junior health minister, at a meeting in April 1981, stated that family planning services provided the entry point for interventions that have the greatest impact:1 whilst any "attempt to restore family values by the wholesale curtailment of availability of contraceptive advice" would be "an irresponsible and blind act of faith", he felt that teenagers should be informed that "the option of chastity is not a vestigial concept of the 19th century". It was acknowledged that "sex was not a disease, neither was it unnatural" and that young people might initiate sexual activity only when they are ready for it but conceded that this rationale was all too often not acceptable to adults. At the same meeting, Dr Duncan Catterall, consultant in genitourinary medicine at the Middlesex Hospital in London, pointed out the potential role of resistant sexually transmitted organisms from two large foci in West Africa and Southeast Asia. However, he was hopeful that "the use of vaccines, which were currently being developed, would bring STD under control again" and anticipated ethical issues such as "should a mother take all her daughters to be vaccinated and who would pay for such prophylaxis". ${ }^{1}$ Those ethical issues are likely to be faced in a substantial manner, for the first time, in the next few months with the introduction of human papillomavirus vaccination in early adolescence. The specific mention of daughters to the exclusion of sons raises issues such as recognition of the increased vulnerability of female teenagers from both biological and social factors, the need for equitable services for addressing gender disadvantage and, finally, an indication of the subtle and subdued attention to male reproductive health services.

At the time, clinics that provided contraceptive services to the young and unmarried often attracted individuals who sought advice for genital conditions such as vaginal discharge: the introduction of infection testing for instant referral was most successful for "accurate diagnosis" and not "clinical guesswork" for "correct treatment and to avoid needless over-prescribing". ${ }^{2}$ Referrals were made for the treatment of "venereal disease (gonorrhoea and syphilis)" but the rarity of gonorrhoea in family planning clinics most likely reflected the profile of individuals being served at that time. ${ }^{3}$

J Fam Plann Reprod Health Care 2006; 32(4): 262-264

\section{Larchmont, USA \\ Lindsay Edouard, FRCOG, FFFP, Member of the Editorial Advisory Board}

Correspondence to: Professor Lindsay Edouard. E-mail:soranae@gmail.com

\section{Condom conundrum}

The origin of the word condom has been associated with the family name, possibly Cundum, of a purveyor of that commodity to King Charles II but it is more likely to be derived from the Latin word condus for receptacle. The quest for condoms has been largely driven by fears of the acquisition of STIs as opposed to contraception: the goat bladder supposedly used around AD 150 by King Minos of Crete, the linen sheath developed during the syphilis epidemic around 1550 by Gabriello Fallopio besides its chemical impregnation soon afterwards by Hercules Saxonia and, finally, the references in the 18th century by Casanova and James Boswell to armour and safe implements, respectively.

Major progress in the industrial production of condoms occurred with the vulcanisation of crepe rubber in 1844 and use of liquid latex in 1922. Condoms were popular for the prevention of STIs during the two world wars and the women's movement led to their increasing use for contraception. However, in the 1960s, accessibility to effective hormonal contraception and availability of microbial therapy led to relegation of the condom to the backwaters of sexual health where it regained its notoriety as a means of avoiding infections in high-risk encounters.

\section{Value of condoms}

With the reorganisation of the National Health Service in 1974 , directives in a circular ${ }^{4}$ had specified that payment should not be made by individuals for "all forms of contraceptive substances and appliances ... including those for the rhythm and other methods, generally referred to as 'non-medical', eg the sheath, creams, etc.". With the decision by the British Medical Association that condoms would not be prescribed by family practitioners, the availability of free condoms was mostly limited to family planning clinics. The provision of condoms to only $2 \%$ of clients of those clinics could have been due to the preference of men for privacy in procuring supplies without any involvement of health staff. However, posing as a new patient, a medical student documented considerable hurdles in a substantial number of clinics to his requests for free condoms.

The Mechanical Contraceptives Committee of the British Standards Institute was an active partner in an international collaboration to set standards for condoms, diaphragms and intrauterine devices. The aim was the provision of quality supplies in developing countries by replacing country-specific standards with international ones..$^{5}$ Awareness of quality testing was also important in Britain, with persistent myths such as a legal requirement for one in twelve condoms to be defective and the introduction of pin-sized holes in condoms by Catholic workers. Condoms were definitely not in the frontline of contraception in the early 1980 s.

On 5 June 1981, the first report of what we now know to be the acquired immunodeficiency syndrome (AIDS) was published: 6 documenting an unusual cluster of five gay men in Los Angeles, the article was not given prominence through its title and placement within the publication to avoid upsetting sensitivities. ${ }^{7}$ More than 25 years later, a vaccine for HIV is still being awaited eagerly. The hopes that had been expressed by Dr Catterall only a few weeks earlier reflected the extraordinary success in the 
development of a vaccine against hepatitis B, and in June 1981 the ramifications for the emerging AIDS epidemic were major. ${ }^{7}$

Through its associations, AIDS was soon considered to be a disease of the Hs: homosexuality, heroin, haemophilia and Haiti. Having become prominent only with recognition of the sexual transmission of HIV, condoms continue to be the mainstay for the prevention of HIV. The Government Accountability Office of the United States, which carries out investigations for the Congress, has expressed concern that one-third of the government funds for HIV prevention programmes should be directed at sexual abstinence until marriage and faithfulness afterwards. ${ }^{8}$ Ideology should not trump scientific evidence on the value of condoms as opposed to the other two components of the $\mathrm{ABC}$ approach: Abstain and Be faithful.

Robust epidemiological studies have exploited numerous opportunities to investigate the value of male latex condoms for contraception and the prevention of STIs in women and men..$^{9,10}$ With the overwhelming evidence of the value, when used consistently and correctly, of the male latex condom, the onus is on policymakers and service providers to promote their utilisation by making them readily and easily available. In the legal brothels of Nevada in the USA, sex workers are forced by law to use condoms and the prevention of HIV transmission has been effective. ${ }^{11}$

\section{Management of infections}

The promotion of condoms has faced major programmatic issues as to whether the target is infection or pregnancy. ${ }^{12,13}$ Cardinal Martini, in the weekly L'espresso of 21 April 2006, specified the potential role of condoms for medical treatment, instead of contraception, for protection of the yet uninfected partner in a HIVserodiscordant couple. Conversely, young people in Uganda currently consider their utilisation of condoms as being primarily for contraception as opposed to infection prevention. ${ }^{14}$ Marie Stopes promoted dual protection by stating that "use of the condom appears almost imperative ... in cases of suspected venereal infection ... so as to prevent pregnancy and to reduce somewhat the risk of infection". But believing in the "benefit to be derived from complete coitus ... achieved through the venereal orgasm together with the effects of absorption through the vagina", she was against routine use of the condom as it "robs the woman of contact with the seminal secretions and this is detrimental to her". 15

Another link between infection and pregnancy exists for diagnosis with the earliest visualisation of both bacteria and sperms, using microscopes around 1677 by Antoni van Leeuwenhoek and Robert Hooke who had close working interactions regarding "animalcules" and "small wrigling creatures" in the liquor of "Semine animalium". Physicist, astronomer and Curator of Experiments of the Royal Society, Robert Hooke recorded minutes of its meetings and notes from his own experiments in a manuscript that was recovered recently from a cupboard in a private house in Hampshire. A prompt auction, planned for 28 March 2006 in London, was avoided at the last hour when the sum of $£ 1$ million was raised by a campaign of the Royal Society with generous support from The Wellcome Trust. The Hooke Folio is being transcribed and digitised to enable electronic access. ${ }^{16}$

Performed at the bedside, microscopy continues to be a useful step in the diagnosis of certain reproductive tract infections. Major diagnostic challenges are still being faced, as exemplified by the debate on the value of the syndromic approach: a critical review led to the

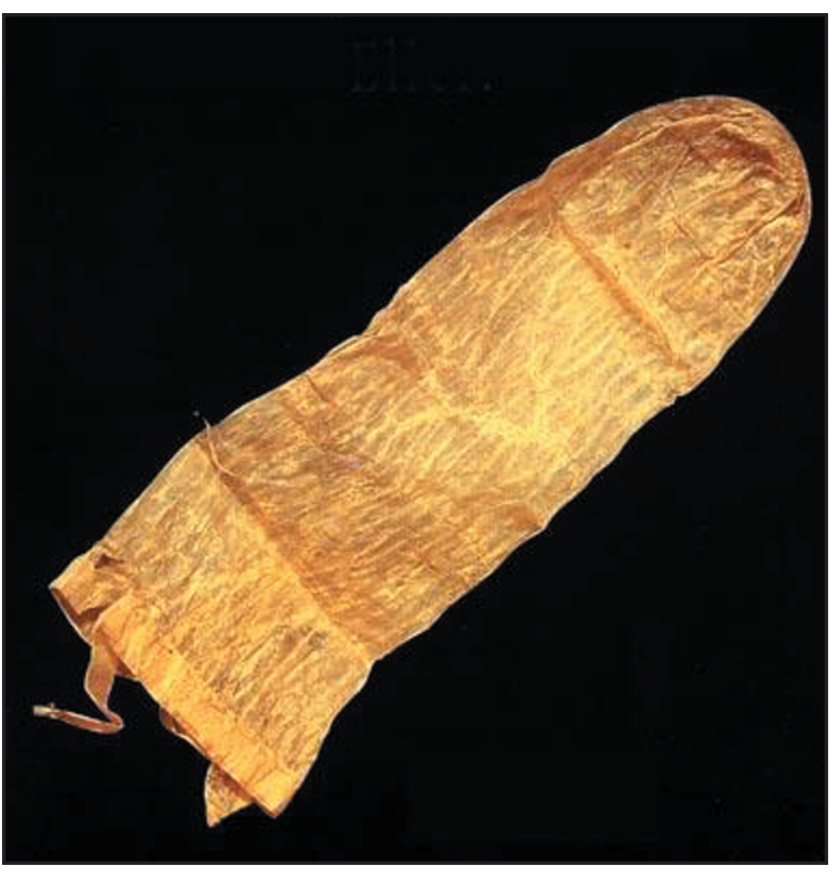

Figure 1 Thought to date from around 1640, the oldest known condom is made of pig intestine and has a silk tie to prevent slippage. Handwritten in Latin, the instructions state that, prior to use, the condom should be soaked in warm milk to prevent disease. Photograph courtesy of the Historic Museum of the University of Lund, Lund, Sweden, and reproduced with their permission. (C) LUHM

development of improved algorithms for the management of several common syndromes, as incorporated by the World Health Organization in its recent guide to essential practice for the clinical management of STIs. ${ }^{17}$

\section{Diversity in condoms}

Latex constitutes an effective barrier that is not permeable to spermatozoa, Neisseria gonorrhoeae, Chlamydia trachomatis and viruses such as HIV and hepatitis B. Unfortunately, the mistaken belief of the normal existence of pores in latex condoms ${ }^{13}$ undermines their value for dual protection despite the rigorous specifications for quality assurance that stipulate testing for freedom from holes during the manufacturing process. ${ }^{18}$ However, leakage can occur as a result of slippage and breakage, and it is often difficult to differentiate user from product failure in determining method effectiveness.

The production of female and male condoms that started in the 1990s using thermoplastic elastomers such as polyurethranes is valuable in providing a choice to the individual, especially in specific situations such as allergy to latex. As a female-controlled barrier method, ${ }^{19}$ the female condom changes gender dynamics by altering the scenario of negotiations for wearing the male condom. A second-generation version of the female condom, made of nitrile instead of polyurethrane, should be available in the near future at a much reduced price.

Condoms have been promoted through numerous features such as ribbed and dotted texture, contoured and flared shape, lubrication, colour, fragrance and flavour besides different sizes for both length and width. Social marketing for improving their availability has been complemented by public activities to increase their familiarity as exemplified by their use for carrying water and contests for blowing them. Health promotion has great potential for improving the utilisation of condoms through positive approaches, with emphasis on pleasure, ${ }^{20}$ to sexual health. Lately, male condoms have been successfully used in emergency obstetric care for hydrostatic tamponade. ${ }^{21}$ When uterotonic agents fail to 
control postpartum haemorrhage due to uterine atony, hysterectomy can be avoided through a tamponade: packing with meticulous layers of ribbon gauze or inflating a large balloon whose natural fit with the uterine lining leads to pressure on the uterine sinuses for controlling the bleeding. Whereas stomach or urological balloons have hitherto been used, the male condom provides a much cheaper and more accessible device that is inflated with isotonic saline solution to provide the hydrostatic pressure. With the new indication for male condoms in the control of postpartum haemorrhage, ${ }^{21}$ we should look forward to further innovative uses for both female and male condoms.

Statements on funding and competing interests

Funding. None identified.

Competing interests. None identified.

References

1 Merry P. The consequences of teenage sexual activity. $\mathrm{Br} J$ Fam Plann 1981; 7: 55-56.

2 Brierley AFM. Genital infection testing at the Birmingham Brook Advisory Centre. Br J Fam Plann 1981; 7: 17-19.

3 Sparks RA, Purrier BGA, Watt PJ, Elstein M. Does gonorrhoea exist in family planning clinics? Br J Fam Plann 1981; 7: 15-17.

4 Howard G, Whittaker I. Difficulties in obtaining condoms on the NHS. Br J Fam Plann 1981; 7: 12-15.

5 Smith M. International Standards Organisation - a meeting in Sri Lanka, February 1981. Br J Fam Plann 1981; 7: 55.

6 Centers for Disease Control. Pneumocystic pneumonia - Los Angeles. MMWR 1981; 30: 250-252.

7 Shilts R. And The Band Played On: Politics, People and the AIDS Epidemic. New York, NY: St Martin's Press, 1987; 66-69.

8 United States Government Accountability Office. Global Health Spending Requirement Presents Challenges for Allocating Prevention
Funding Under the President's Emergency Plan for AIDS Relief. Document GAO-06-395. Washington, DC: United States Government Accountability Office, 2006; 14, 44-46.

9 Holmes KK, Levine R, Weaver M. Effectiveness of condoms in preventing sexually transmitted infections. Bull WHO 2004; 82: 454-461

10 Steiner MJ, Cates W. Condoms and sexually-transmitted infections. $N$ Engl J Med 2006; 354: 2642-2643.

11 Albert AE, Warner DL, Hatcher RA, Trussell J, Bennett C. Condom use among female commercial sex workers in Nevada's legal brothels. Am J Public Health 1995; 85: 1514-1520.

12 The Pope's grievous errors (Editorial). Lancet 2005; 365: 912.

13 Condoms and the Vatican (Editorial). Lancet 2006; 367: 1550.

14 Wakabi W. Condoms still contentious in Uganda's struggle over AIDS. Lancet 2006; 367: 1387-1388.

15 Stopes MC. Contraception: Its Theory, History and Practice. A Manual for the Medical and Legal Professions (8th edn). London, UK: Putnam, 1952; 32, 159-160.

16 Royal Society. Long lost manuscript of forgotten scientist returns to the Royal Society (press release). London, UK: The Royal Society, 17 May 2006.

17 World Health Organization. Sexually Transmitted and Other Reproductive Tract Infections - A Guide to Essential Practice. Geneva, Switzerland: World Health Organization, 2005; 98, 168.

18 World Health Organization, Joint United Nations Programme on HIV/AIDS, United Nations Population Fund and Family Health International. The Male Latex Condom: Specification and Guidelines for Condom Procurement. Geneva, Switzerland: World Health Organization, 2004; 18-30.

19 World Health Organization and Joint United Nations Programme on HIV/AIDS. The Female Condom - A Guide for Planning and Programming. Document WHO/RHR/00.8. Geneva, Switzerland: World Health Organization, 2000; 17-18, 25, 37.

20 Venis S. Lunch with The Lancet - Anne Philpott. Lancet 2005; 365: 565 .

21 Akhter S, Begum MR, Kabir J. Condom hydrostatic tamponade for massive postpartum hemorrhage. Int J Gynaecol Obstet 2005; 90: 134-135.

\section{News Roundup}

\section{NHS cuts hit sexual health services}

Genitourinary medicine (GUM) units across the country have been forced to abandon plans to develop services due to budget cuts at PCT level. Any growth money available after the 3\% budget cut can only be spent on the six key priorities laid out in the NHS operating framework document. For example, 48-hour access to GUM services is included in that list but chlamydia screening is not. The British Association of Sexual Health and HIV (BASHH) has discovered that at least 64 GUM providers have had difficulty getting any of the funds allocated to develop their services, despite a 2004 government pledge to plough $£ 300$ million into the sexual health sector. Jamie Hardie, President of the Society of Sexual Health Advisers, said he was worried this was going to be the pattern in other areas where chlamydia screening was due to have started: "On the one hand the government trumpets spending on [chlamydia] screening as part of its $£ 300$ million sexual health plans and, on the other hand, chlamydia screening that was budgeted for and planned for may have just been quietly postponed".

Source: http://www.publichealthnews.com/news/showcontent. asp?id= $\{$ F9F27BFC-D251-4D94-AAB1-F948C22A60A4 $\}$

Reported by Henrietta Hughes, MRCGP, DFFP $G P$, London, $U K$

\section{International fertility survey}

Despite increasing media attention on the subject of fertility, public knowledge of reproductive health is remarkably low, according to a new international survey. This finding emerged from the first international fertility survey 'What You Never Knew About Fertility' carried out as part of World Fertility Awareness Month and sponsored by Organon.
The survey revealed an important lack of knowledge on 15 questions including the effects of age, contraception and the general health on fertility. When these questions were posed to 17500 individuals worldwide, not one scored $100 \%$. In fact, less than half of respondents were aware of the age at which female fertility starts to decline or the impact that factors such as obesity and sexually transmitted infections have on fertility preservation.

For more information and to obtain a brochure visit www.organon.com and for more information on fertility visit www. fertilityjourney.com.

Reported by Henrietta Hughes, MRCGP, DFFP GP, London, UK

\section{Public lack knowledge of HIV}

A recent survey of over 2000 Britons over the age of 15 years showed a lack of knowledge regarding transmission of HIV. ${ }^{1}$ The survey, commissioned by the National AIDS Trust, showed that many of the people surveyed were unaware that HIV could be passed on through unprotected sex, and that $15 \%$ would rarely or never use a condom with a new partner. Only $10 \%$ would undergo testing for HIV before ceasing condom use in a new relationship.

\section{Reference \\ Public lack knowledge of HIV (News item). The Pharmaceutical Journal 2006; 276: 559.}

Reported by Henrietta Hughes, MRCGP, DFFP GP, London, UK

\section{Dianette $^{\circledR}$ and depression}

The Medicines and Healthcare products Regulation (MHRA) agency is to investigate depression in women taking Dianette ${ }^{\circledR}$ (cocyprindiol) after the Adverse Psychiatric Reactions Information Link (APRIL) charity raised concerns. The charity has sent a dossier to the MHRA of reports from 100 women who said they experienced severe depression while on the drug. The MHRA have stated that depression is a known side effect of the drug and this is included in the product information leaflet. They are undertaking a review to see if the advice needs updating or changing.

Source: http://www.april.org.uk/

Reported by Henrietta Hughes, MRCGP, DFFP GP, London, UK

\section{Ghana vasectomy study}

A recent project has been undertaken in Ghana to increase awareness of, access to, and utilisation of vasectomy services. Vasectomy in Ghana has a prevalence of less than $0.1 \%$. Addressing both the supply and demand side issues that have contributed to the under-utilisation of vasectomy, the project aimed to increase the access to, and quality of, services in addition to tackling the negative myths and rumours about vasectomy among men and the general public and the bias against the method among providers. Interventions included training clinicians on noscalpel vasectomy, training site staff in male-friendly services, developing and implementing a media campaign, conducting community outreach, and establishing an informational hotline. Results indicate the project was successful in increasing awareness of, access to, and utilisation of vasectomy services. In 2004, service volume was 6.6 times higher than the average number of procedures provided in the 10 years prior to the project (1994-2003). The number of men aware of vasectomy nearly doubled, and men's 'intention to consider vasectomy' also doubled.

Source: http://www.acquireproject.org/index. php?id=344

Reported by Henrietta Hughes, MRCGP, DFFP GP, London, UK 